BIOMEDICAL AND BIOSOCIAL ANTHROPOLOGY
$\begin{gathered}\text { Official Journal of the International Academy } \\ \text { of Integrative Anthropology } \\ \text { journal homepage: http://bba-journal.com }\end{gathered}$

\title{
Peculiarities of aeromedical evacuation of wounded and sick and ways of its improvement based on the experience of anti-terrorist operation and joint forces operation
}

\author{
Babii V. Yu. ${ }^{1}$, Verba A. V. ${ }^{2}$, Pashkovskyi S. M. ${ }^{1}$
}

${ }^{1}$ Military medical center of the Central region, Vinnytsya, Ukraine

${ }^{2}$ National Pirogov Memorial Medical University, Vinnytsya, Ukraine

\section{ARTICLE INFO}

Received: 09 September, 2020

Accepted: 12 October, 2020

UDC: $355.415 .6: 614.2$

\section{CORRESPONDING AUTHOR}

e-mail: dr.vadim.babii@gmail.com Babii V. Yu.

\begin{abstract}
The article is describing general principles of organization of aeromedical evacuation of the patients by helicopters directly from the battlefield area. The number and nature of casualties caused by military aggression determined the organizational and functional features of aeromedical evacuation from the zone of military conflict. The purpose of the study is to investigate demographic, clinical, chronometric and economic indicators of air medical evacuation from the zone of military conflict and between hospitals within Ukraine to create, based on their global analysis, the optimal organizational and functional model of air medical evacuation in Ukraine. Created database, which filled out from various sources. Leading syndromes grouped the diagnoses with which the patients transported. Method of analysis known as an XmR chart used to study dynamic of the aeromedical evacuation process, which is one tool from a collection of methods known as statistical process control. The aeromedical evacuation system must be able to evacuate a sufficiently large number of stable patients from anywhere on the line of contact, and be flexible to respond in the event of a relatively small number of very unstable patients in the area of hostilities who need to be evacuated quickly enough. The obtained statistics can be useful for short- and medium-term planning of the aeromedical evacuation service. The configuration and operation of aeromedical units always depends on the nature and specificity of the military conflict, but the planning of deployment and determination of requirements of means for aeromedical evacuation should always base on the analysis of previous experience.
\end{abstract}

Keywords: military casualties, helicopter transportation, transportation priority, dependence from medical support.

\section{Introduction}

Russia's armed aggression in May 2014 created the preconditions for the deployment of the Armed Forces in eastern Ukraine. The deployment of the armed forces took place as part of the anti-terrorist operation (ATO), which later, in May 2018, was transformed into the Joint Forces Operation (JFO). The amount and nature of sanitary losses resulting from these two combat operations caused and caused unprecedented changes in the provision of military medical care by the medical service of the Armed Forces of Ukraine, which was later transformed into the Medical Forces as a type of armed forces [20].

Understanding the factors that determine the course of aeromedical evacuation contributes to the optimal use of medical resources for the benefit of the patient and the success of the aeromedical mission as a whole [10,11].
Continuity of high-tech medical care from the battlefield to the final medical facility, together with aeromedical evacuation has become a fundamental element of the transformation of the medical service as a result of these military operations [9].

The purpose of military aeromedical evacuation is to ensure rapid movement of sick and injured patients over long distances to a higher level of medical care, reduce morbidity and mortality, rapid unloading of medical facilities close to the line of contact, increase their capacity and mobility $[13,18]$.

Aeromedical units of the Medical Forces are responsible for the aeromedical evacuation of military and civilians both from the zone of military conflict in eastern Ukraine and between regional centers within the country. They carry out 
aeromedical evacuation of about 2,000 patients a year, which is the largest indicator among departmental medical services and medical institutions of the Ministry of Health in the single medical space of Ukraine.

The peculiarity of aeromedical evacuation is that the complex relationship between military operations, logistics and personnel of aeromedical units has a negative impact on the speed of creating a single, integrated and effective system of aeromedical evacuation.

Understanding the factors that determine the course of aeromedical evacuation contributes to the optimal use of medical resources for the benefit of the patient and the success of the aeromedical mission as a whole.

The purpose of the study is to investigate demographic, clinical, chronometric and economic indicators of air medical evacuation from the zone of military conflict and between hospitals within Ukraine to create, based on their global analysis, the optimal organizational and functional model of air medical evacuation in Ukraine.

\section{Materials and methods}

A database was created and processed, which was filled from various sources: reports of aircraft crews, requests for aeromedical evacuation, logs of registration and accounting of transports of aeromedical units, maps of patient transports. The database contained information on the aeromedical evacuation of the wounded and sick for the period from 2015 to 2019. Data on the patient's gender, place of service, route and time of transportation, diagnoses, evacuation priorities, category of dependence on medical care and position on board during the evacuation were collected.

The priority of evacuation was determined by NATO standardized agreement (STANAG 3204) [13], with priorities 1,2 and 3 being urgent, priority and routine evacuation. Priority I (Emergency) usually requires evacuation within 1 to 4 hours to 24 , Priority II within 24-48 hours, and Priority 3 within 7 days. The category of dependence on in-flight medical support was determined according to the need for observation, treatment and care, namely: levels I-IV corresponded to high, medium, low and minimum dependence [12]. Examples of category I (high) dependence on medical care may be a patient undergoing artificial lung ventilation, pressure support of hemodynamics, pleural drainage with active negative pressure, etc.

The diagnoses with which the patients were transported were grouped according to the leading syndromes into seven groups, as this made it possible to group disparate diagnoses by linking them causally with combat. The combat sanitary losses included: gunshot wounds, mine injuries and laser retinal burns. But non-combat injuries and diseases included: acute poisoning, infectious diseases, other therapeutic diseases, other surgical diseases, non-combat trauma, burns and cardiovascular diseases (acute cerebrovascular disorders, hereinafter $A C A$, and acute coronary syndromes hereinafter - ACS).
Burns and non-combat injuries were divided into separate groups, as the routes of aeromedical evacuation were different in these pathologies.

Clinical and demographic characteristics were summarized as frequency distribution (absolute and percentage). Because the distribution of the data was not known a priori, a method of analysis known as $\mathrm{XmR}$ maps was used to study the patterns associated with change over time. XmR-maps are a tool from a set of methods known as statistical process control [4, 14].

Statistical process control charts display process data over time, using three elements: the median, the mean, and two lines, which are typically approximately \pm 3 SD of the mean, to indicate the upper and lower limits of the natural process. A feature of XmR maps is that they use the difference between successive values (ie moving ranges) to determine the natural boundaries of the process. When data points appear without any unusual patterns and within the process, the process is said to reflect a general trend and is considered statistically controlled (stable). When the points go beyond or there are unusual data patterns, the process is said to exhibit special causes of variation, indicating a change in the data acquisition process. When there is data on medium- and long-term process changes, the limits are recalculated for the data before and after the change, thus quantifying the changes.

\section{Results}

During the period from May 2014 to October 2020, about 1,668 helicopter flights were made for aeromedical evacuation in the immediate vicinity of the collision line. During this period, 8249 wounded and sick were transported accompanied by aeromedical teams. Of these, demographic and clinical information was obtained for 1338 (16.2\%) patients (Table 1), the remaining 6911 patients were excluded from the analysis.

The average age of transported patients from the specified analyzed sample was $36.8 \pm 16.2$ years. The

Table 1. Demographic characteristics of evacuated patients $(n=1338)$.

\begin{tabular}{|c|c|c|c|c|c|c|c|}
\hline \multirow{2}{*}{ Indicator } & \multicolumn{2}{|c|}{$\begin{array}{c}\text { The total } \\
\text { number of } \\
\text { evacuees }\end{array}$} & \multicolumn{2}{|c|}{$\begin{array}{c}\text { Combat } \\
\text { sanitary } \\
\text { losses }\end{array}$} & \multicolumn{2}{c|}{$\begin{array}{c}\text { Non-combat } \\
\text { injuries and } \\
\text { diseases }\end{array}$} \\
\cline { 2 - 8 } & $\mathrm{n}$ & $\%$ & $\mathrm{n}$ & $\%$ & $\mathrm{n}$ & $\%$ \\
\hline \multirow{3}{*}{ Sex } & women & 42 & 3.14 & 4 & 0.30 & 38 & 2.84 \\
\cline { 2 - 9 } & men & 1296 & 96.86 & 598 & 44.69 & 698 & 52.17 \\
\hline \multirow{4}{*}{ Priority } & emergency & 167 & 12.48 & 118 & 8.82 & 49 & 3.66 \\
\cline { 2 - 9 } & urgent & 459 & 34.30 & 266 & 19.88 & 193 & 14.42 \\
\cline { 2 - 8 } & planned & 712 & 53.21 & 218 & 16.29 & 494 & 36.92 \\
\hline \multirow{3}{*}{$\begin{array}{c}\text { Category of } \\
\text { dependence } \\
\text { on medical } \\
\text { support }\end{array}$} & $\mathrm{I}$ & 282 & 21.08 & 195 & 14.57 & 87 & 6.50 \\
\cline { 2 - 8 } & $\mathrm{II}$ & 213 & 15.92 & 125 & 9.34 & 88 & 6.58 \\
\cline { 2 - 8 } & $\mathrm{III}$ & 487 & 36.40 & 190 & 14.20 & 297 & 22.20 \\
\cline { 2 - 8 } & 356 & 26.61 & 92 & 6.88 & 264 & 19.73 \\
\hline
\end{tabular}




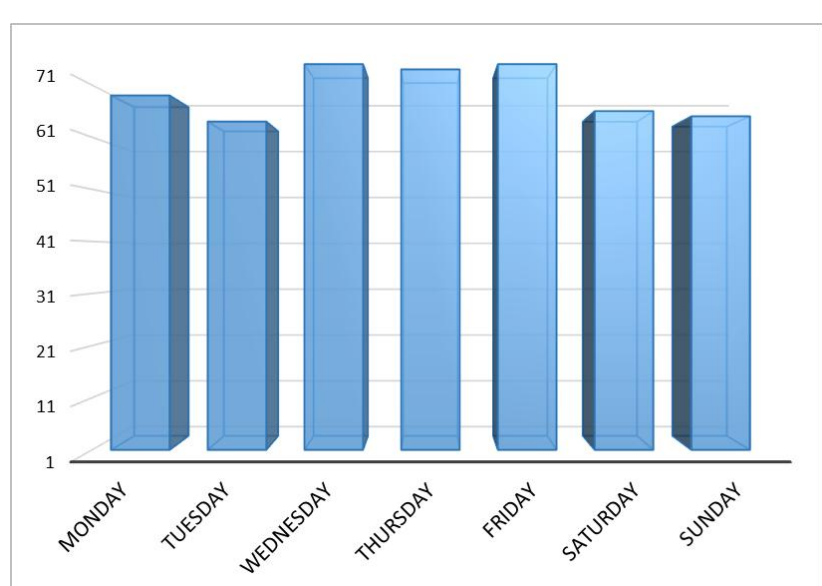

Fig. 1. Distribution of the number of departures by days of the week (510 departures).

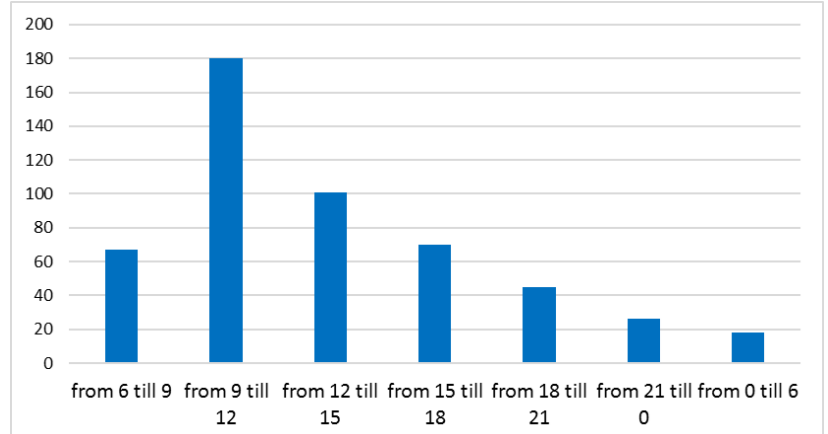

Fig. 2. Distribution of the number of departures by hours of the day (510 departures).

number of patients transported per flight ranged from 1 to 13 patients and averaged $2.6 \pm 2.2$ patients per flight (number of patients 1338, number of departures 510 , followup 24 months).

The number of patients with the priority of evacuation "Emergency" who need the fastest evacuation to save lives, prevent life-threatening complications or avoid organ loss was $12.48 \%$ of the total number of evacuees and was more than twice as high ( $8 \%$ of combat units). in the group of non-combat injuries and diseases (3.66 \%).

It should be noted that the number of patients with high dependence on medical care (patients with anesthesia monitoring, mechanical ventilation and/or pressurized hemodynamic support) was $21.08 \%$ of the total number of transported and was significantly higher in the group of combat health losses $(14.57 \%)$ in comparison with the group of non-combat injuries and diseases (6.50\%).

For the correct organization of the process, the rational use of human resources of air medical evacuation, it is necessary to have an idea of the chronometric indicators, on what day of the week and at what time of day the maximum load on medical and aviation personnel.

Figure 1 shows the distribution of departures by days of the week, which shows that departures were distributed differently by days of the week, with the lowest number of departures on Tuesdays (64 departures) and increasing by almost $35.0 \%$ on Wednesdays and Fridays

As for the time of day, it gradually increased from 6 to 9 am, reaching a peak from 9 to 12 am $(35.5 \%$ of all departures), gradually decreasing to night hours $(0-6 \mathrm{am})$, when the number of departures was the lowest $(3.5 \%$ of all departures) (Fig. 2).

As can be seen from Table 2, the leading place among combat sanitary losses was taken by mine-explosive trauma (30.72 \%), among non-combat injuries and diseases surgical diseases (15.02\%), non-combat trauma $(13.90 \%)$ and therapeutic diseases $(13.38 \%)$ prevailed.

Analysis of the dynamics of the process of aeromedical evacuation (AME) for 2018-2019, was conducted by XmRmap (Fig. 3). During this period, the AME process did not show significant monthly fluctuations in the total number of evacuations from the ATO/JFO zone during the period January 2018 - December 2019. The average number of evacuations $(\bar{X})$ was 55.8 per month, while the upper limit of evacuations $\left(\mathrm{UNPL}_{\mathrm{X}}\right)$ was 112.2 evacuations per month (the lower limit of this process $\left(\mathrm{LNPL}_{x}\right)$ was close to zero and therefore uninformative).

The trend line, calculated for January 2018 - December 2019 , had a gradient of 1.65 , which means that on average during this period, there were 1.65 fewer evacuations per month than in the previous month; accordingly, the monthly evacuation rate decreased by 19.8 per year. In April 2018, there was an excessive number of evacuations that went beyond the general trend, and from September 2018 to December 2018 there was a significant deviation from the previous trend, and the number of evacuations was less than expected if the previous trend continued.

During the same period, the AME process of patients of category I dependence on medical support was analyzed (patients who require intensive monitoring and/or mechanical ventilation and/or pressure support of hemodynamics, as well as anesthesiologist support).

Analysis of the dynamics of the process of aeromedical evacuation (AME) for 2018-2019, was conducted on an

Table 2. Distribution of evacuated patients by leading syndromes $(n=1338)$.

\begin{tabular}{|c|c|c|c|}
\hline Leading syndrome & $\mathrm{n}$ & $\%$ & $\begin{array}{l}\text { The nature of } \\
\text { sanitary losses }\end{array}$ \\
\hline Gunshot wounds & 186 & 13.90 & \multirow{3}{*}{$\begin{array}{l}\text { Combat sanitary } \\
\text { losses - } 44.99 \%\end{array}$} \\
\hline Mining and explosion injury & 411 & 30.72 & \\
\hline Laser retinal burns & 5 & 0.37 & \\
\hline Other surgical & 201 & 15.02 & \multirow{7}{*}{$\begin{array}{c}\text { Non-combat } \\
\text { injuries and } \\
\text { diseases - } \\
55.01 \%\end{array}$} \\
\hline Non-combat trauma & 186 & 13.90 & \\
\hline Other therapeutic & 179 & 13.38 & \\
\hline $\begin{array}{l}\text { Cardiovascular diseases (ACD, } \\
\text { ACS) }\end{array}$ & 75 & 5.61 & \\
\hline Infectious diseases & 36 & 2.69 & \\
\hline Acute poisoning & 32 & 2.39 & \\
\hline Burns & 27 & 2.02 & \\
\hline
\end{tabular}




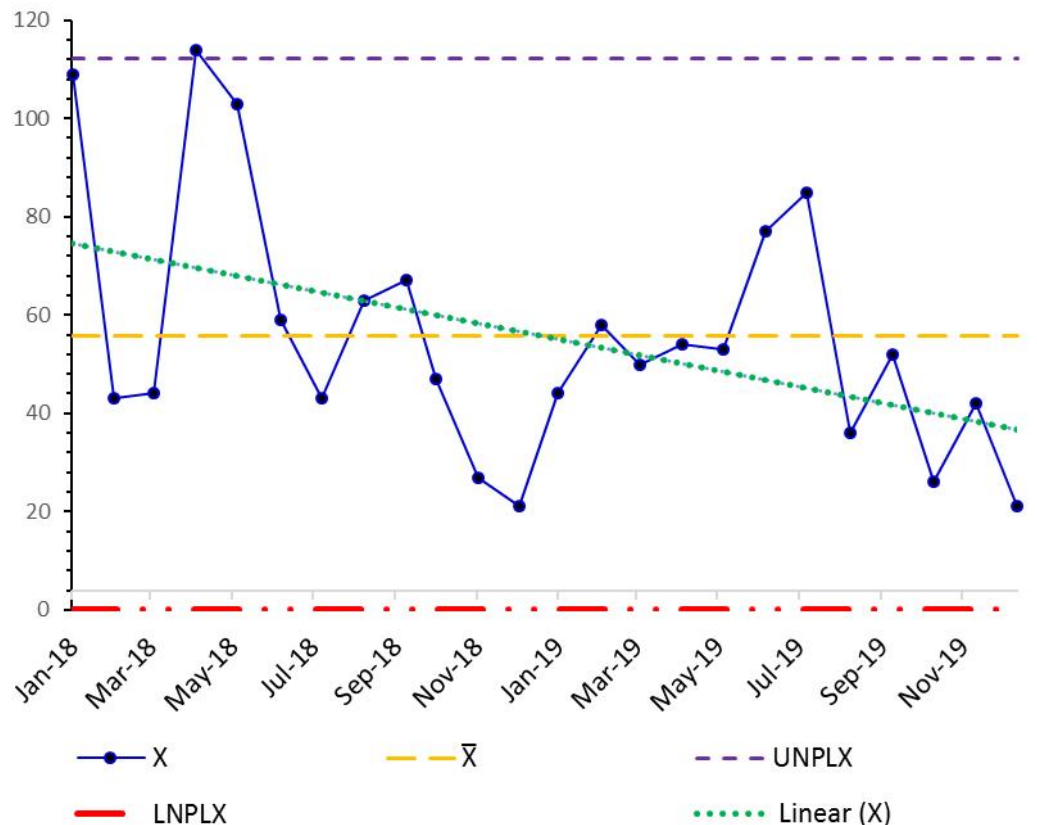

Fig. 3. The total number of monthly aeromedical evacuations from the ATO/JFO zone with the number of transported patients (XmR-maps) for 2018-2019. The interval between the aeromedical evacuation process is the expected range of fluctuations in the number of evacuations in the respective time periods.

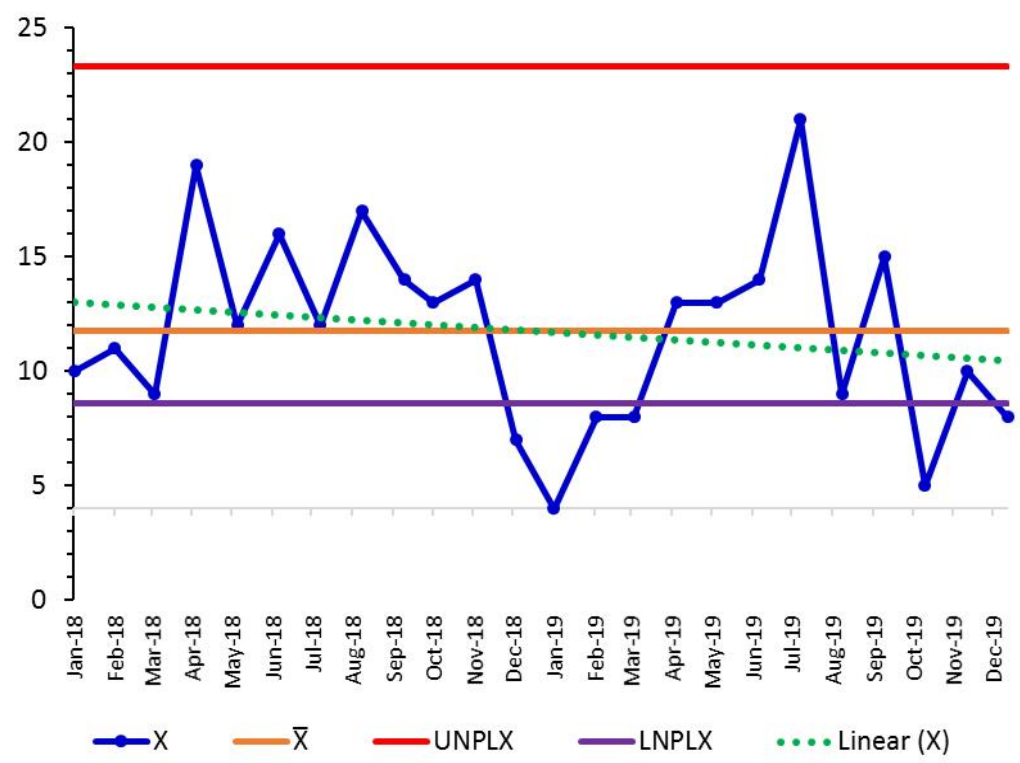

Fig. 4. Monthly number of aeromedical evacuations of patients of category I (high dependence on medical support) from the ATO/JFO zone by months with the number of transported patients (XmR-cards) for 2018-2019.

XmR-map (Fig. 4). During this period, the process of evacuation of patients of the I category of dependence on medical support had significant fluctuations. The average number of evacuations of category I $(\overline{\mathbf{X}})$ patients was 11.8 per month, with the lower fluctuation limit of this process (LNPLx) being 8.6 evacuations per month, and the upper limit of fluctuations in the number of evacuations (UNPLx) being 23.3 evacuations per month.

The trend line calculated for this category of patients as well as for the total number of evacuees was downward, its gradient was 0.11 , which means that on average during this period, there were 0.11 fewer evacuations of category I patients per month than in the previous month; accordingly, the monthly evacuation rate of such patients decreased by 1.32 per year. Too low, which exceeded the lower limit of the natural process of AME (LNPLx), the monthly number of evacuations of patients with high dependence on medical care was observed in December 2018 (7), January 2019 (4), February 2019 (8) and March 2019 (8). Similar fluctuations with the lower limit (LNPLx) of the aeromedical evacuation process were observed in October 2019 (5) and December 2019 (8). It should be noted that beyond the upper limit of fluctuations, the process of aeromedical evacuation for the specified period did not go.

\section{Discussion}

Our study shows that combat and noncombat sanitary losses were approximately the same in the period 2018-2019 in the order of tactical aeromedical evacuation (from frontline field hospitals and stabilization points to medical facilities outside the ATO/ JFO). Regarding the distribution by sex, the number of women evacuated from the ATO/ JFO zone was significantly lower (3.14\%) compared to men $(96.86 \%)$. The sex ratio of women and men transported from the ATO/ JFO area differs significantly from that of evacuated NATO troops during the operation in Iraq and Afghanistan. According to the data evacuated patients by the Royal Air Force, $14.1 \%$ were women; men - $85.9 \%[5,14]$, and among patients evacuated by the United States Air Force $-11.0 \%$ of men $89.0 \%$ [3]. In terms of sex, we have not been able to investigate the return to duty in the war zone, but according to the literature, women are much more likely to return to work than men.

The main reason for the evacuation of women from the ATO/JFO zone was noncombat injuries and illnesses $(90.5 \%)$ compared to combat sanitary losses $(9.5 \%)$ of all transported women.

In the structure of combat sanitary losses in the ATO/ JFO, mine injuries (68.3\%) and gunshot wounds (30.9\%) occurred. This fact may indicate the nature of hostilities, when the opposing parties use mainly mortars, avoiding direct contact. This may also be due to the way in which 
liability for breach of peace agreements is avoided.

Among non-combat injuries and diseases, traumatic injuries accounted for a significant share of $25.3 \%$, the absolute number of such patients was equal to the number of patients with gunshot wounds (186 wounded). These figures emphasize the importance of non-combat injury prevention in troops near the line of contact, as such traumatic injuries are most often caused by violations of safety rules, instructions and statutes $[6,10]$.

If combat trauma is considered a proxy marker of the intensity of hostilities, then for comparison we can correlate these results with a large epidemiological study of US troops serving in the Middle East, in which $14.0 \%$ of personnel evacuated from the theater of operations were diagnosed with combat trauma. [3].

It should be noted that patients with trauma were very resource-intensive. These patients were almost 3 times more likely to be highly dependent on evacuation care than patients with non-traumatic diagnoses, almost $40.0 \%$ of whom were minimally dependent, which did not require specialized medical care. In addition, patients with trauma were more than twice as likely to require an "emergency" evacuation with priority 1 due to life-threatening or limb loss or to avoid permanent disability.

The dramatic and serious nature of combat trauma is beyond doubt, but it is generally accepted that in recent military operations, not only in Ukraine, but also in Iraq and Afghanistan, diseases and non-combat injuries have led to significantly greater depletion of troops $[3,16]$.

War is a dynamic event that requires a complex strategy, logistics and well-trained personnel $[15,19]$. This complexity and continuous development make planning and forecasting difficult. However, as technology evolves and the goals of war shift from destruction and occupation to state-building and cultural transformation, certain trends emerge. For example, we observed a decrease in the total number of injured over time, but the proportion of critically ill patients increased.

Such trends are characteristic of many military conflicts, they are associated with changes in the nature of injuries, the need for medical evacuation of infectious and other therapeutic diseases, as well as non-combat injuries, which consist mainly of spinal disorders and other musculoskeletal disorders that occur during training or recreation $[1,2,7,8$, 17].

The dynamics of the aeromedical evacuation process had slight fluctuations during the period January 2018 December 2019. The total number of transported patients decreased significantly in winter, gradually increased in spring (from April to June) and decreased again in summer. This trend indicates a natural decrease in the intensity of hostilities in the winter, due to the difficulties associated with

\section{References}

[1] Bellamy, R. F. (1995). Anesthesia and perioperative care of the combat casualty. Combat trauma overview. Falls Church, VA: weather conditions. The summer decline in the number of evacuations is associated with the traditional forced ceasefire during the harvest period. Regarding the dynamics of the process of patients in critical conditions, in general, it repeated the fluctuations and trends of the total number of evacuees. It should be noted that in the winter months the process of evacuation of patients of the first category of dependence on medical care was close or exceeded the lower limit of fluctuations in the number of evacuations. And in the spring and summer months of 2018-2019 was close to the upper limit of fluctuations in the number of evacuations. Thus, the evacuation of patients of high dependence on medical care had significant fluctuations. This may indicate that the medical service must be able to increase its capacity suddenly and be flexible in order to increase its capacity to evacuate a large number of critically ill patients with a relatively constant total number of evacuations.

\section{Conclusions}

1. The results of the study emphasize the complexity of planning and implementation of air medical evacuation in conditions of hybrid aggression in eastern Ukraine. The aeromedical evacuation system must be able to evacuate a sufficiently large number of stable patients from anywhere on the line of contact, and be flexible to respond in the event of a relatively small number of very unstable patients in the area of hostilities who need to be evacuated quickly enough.

2. A possible improvement of the adapted system of aeromedical evacuation may be the organization of regular flights to areas with consistently high demand for aeromedical evacuation of patients with low (III-IV) degree of dependence on medical support. Such flights could be staffed by aeromedical crews (AC) consisting of a general practitioner and/or paramedics with appropriate thematic improvement in aeromedical evacuation. The functioning of the system of such aeromedical teams can be combined with the strengthening of their aeromedical intensive care teams (AICT) consisting of anesthesiologists, anesthesiology nurses and, if necessary, other specialists, if required by the clinical situation.

3. Requirements for resource provision of aeromedical evacuation depend on the structure and amount of sanitary losses, they differ significantly during the phase of active hostilities and between them. Planning should be individualized for each military operation, and an aeromedical evacuation system should be developed during these operations.

4. The aeromedical evacuation system should be flexible enough to provide care for both a relatively small number of critically ill category I patients (highly dependent on medical care) and for a much larger number of less dependent patients whose evacuation is less resource-intensive.

Office of the Surgeon General, United States Army, 1-42. [2] Boyd, L. R., Borawski, J., Lairet, J., \& Limkakeng, A. T. (2017). 
Critical care air transport team severe traumatic brain injury short-term outcomes during flight for operation Iraqi freedom/ operation enduring freedom. BMJ Military Health, 163(5), 342346. doi:10.1136/jramc-2016-000743

[3] Cohen, S. P., Brown, C., Kurihara, C., Plunkett, A., Nguyen, C., \& Strassels, S. A. (2010). Diagnoses and factors associated with medical evacuation and return to duty for service members participating in Operation Iraqi Freedom or Operation Enduring Freedom: a prospective cohort study. The Lancet, 375(9711), 301-309. doi: 10.1016/S0140-6736(09)61797-9

[4] Donald Wheeler, J. (2004). Advanced Topics in Statistical Process Control, The Power of Shwehart's Charts. SPC PRESS (Statistical Process Control).

[5] Gawande, A. (2004). Casualties of war - military care for the wounded from Iraq and Afghanistan. New England Journal of Medicine, 351(24), 2471-2475. doi: 10.1056/NEJMp048317

[6] Gray, G., Bron, D., Davenport, E. D., d'Arcy, J., Guettler, N., Manen, O., ... \& Nicol, E. D. (2019). Assessing aeromedical risk: a three-dimensional risk matrix approach. Heart, 105(Suppl 1), s9-s16. doi: 10.1136/heartjnl-2018-313052

[7] Hoeffler, D. F., \& Melton, L. J. (1981). Changes in the distribution of Navy and Marine Corps casualties from W orld War I through the Vietnam conflict. Military medicine, 146(11), 776-779. PMID: 6798499

[8] Holcomb, J. B., Stansbury, L. G., Champion, H. R., Wade, C., \& Bellamy, R. F. (2006). Understanding combat casualty care statistics. Journal of Trauma and Acute Care Surgery, 60(2), 397-401. doi: 10.1097/01.ta.0000203581.75241.f1

[9] Lurin, I. A., Halushka, A. M., Kikh, A. Yu., Shvets, A. V., Lovkin, I. M., \& Horishna, O. V. (2017). Основні завдання та заходи медичної реабілітації в системі медичного забезпечення Збройних Сил України [The main tasks and measures of medical rehabilitation in the system of medical support of the Armed Forces of Ukraine]. Військова медицина України Military medicine of Ukraine, 17(3-4), 11-23.

[10] Maddry, J. K., Arana, A. A., Savell, S. C., Reeves, L. K., Perez, C. A., Mora, A. G., \& Bebarta, V. S. (2017). Critical care air transport team evacuation of medical patients without traumatic injury. Military medicine, 182(11-12), e1874-e1880. doi: 10.7205/MILMED-D-17-00091

[11] Maddry, J. K., Mora, A. G., Savell, S. C., Perez, C. A., Mason, P. E., Aden, J. K., \& Bebarta, V. S. (2018). Impact of Critical Care Air Transport Team (CCATT) ventilator management on combat mortality. Journal of Trauma and Acute Care Surgery, 84(1), 157-164. doi: 10.1097/TA.0000000000001607

[12] Ministry of Defence. (2009). AP3394: The Royal Air Force Aeromedical Evacuation Service (4th ed. London). UK: Ministry of Defence.

[13] Organisation, N. A. T. (1999). STANAG 3204 AMD (edition6): Aeromedical evacuation. Brussels, Belgium: NATO, 15.

[14] Patterson, C. M., Woodcock, T., Mollan, I. A., Nicol, E. D., \& McLoughlin, D. C. (2014). United Kingdom military aeromedical evacuation in the post-9/11 era. Aviation, space, and environmental medicine, 85(10), 1005-1012. doi: 10.3357/ ASEM.4005.2014

[15] Proctor, J. L., Mello, K. T., Fang, R., Puche, A. C., Rosenthal, R. E., Fourney, W. L., ... \& Fiskum, G. (2017). Aeromedical evacuation-relevant hypobaria worsens axonal and neurologic injury in rats after underbody blast-induced hyperacceleration. Journal of Trauma and Acute Care Surgery, 83(1), S35-S42. doi: 10.1097/TA.0000000000001478

[16] Sanders, J. W., Putnam, S. D., Frankart, C., Frenck, R. W., Monteville, M. R., Riddle, M. S., ... \& Tribble, D. R. (2005). Impact of illness and non-combat injury during Operations Iraqi Freedom and Enduring Freedom (Afghanistan). The American journal of tropical medicine and hygiene, 73(4), 713-719. PMID: 16222015

[17] Sperry, J. L., Guyette, F. X., Brown, J. B., Yazer, M. H., Triulzi, D. J., Early-Young, B. J., ... \& Zenati, M. S. (2018). Prehospital plasma during air medical transport in trauma patients at risk for hemorrhagic shock. New England Journal of Medicine, 379(4), 315-326. doi: 10.1056/NEJMoa1802345

[18] Venticinque, S. G., \& Grathwohl, K. W. (2008). Critical care in the austere environment: providing exceptional care in unusual places. Critical care medicine, 36(7), S284-S292. doi: 10.1097/CCM.0b013e31817da8ec

[19] Ursano, R. J., Kessler, R. C., Naifeh, J. A., Mash, H. H., Fullerton, C. S., Aliaga, P. A., ... \& Stein, M. B. (2018). Associations of time-related deployment variables with risk of suicide attempt among soldiers: results from the Army Study to Assess Risk and Resilience in Servicemembers (Army STARRS). JAMA psychiatry, 75(6), 596-604. doi: 10.1001/ jamapsychiatry.2018.0296

[20] Verba, A. V. (2016). Стан та проблемні питання медичного забезпечення в зоні проведення антитерористичної операції в різні періоди [The state and problematic issues of medical care in the area of the anti-terrorist operation in different periods]. Медичне забезпечення антитерористичної операції: науково-організаційні та медико-соціальні аспекти: збірник наукових праць - Medical support of the anti-terrorist operation: scientific-organizational and medical-social aspects: a collection of scientific works. K, 15-24. 